\title{
Effect of catalyst morphology and hydrogen co-feeding on the acid-catalysed transformation of acetone into mesitylene
}

Received 00th January 20xx, Accepted 00th January 20xx DOI: $10.1039 / \times 0 \times x 00000 x$

\author{
Jorge Quesada, Laura Faba, Eva Díaz and Salvador Ordóñez*
}

The application of different aluminosilicates (MCM-41, MFI, BEA) to catalyse the gas-phase self-condensation of acetone allows the selective formation of mesitylene regarding the rest of C9 compounds (relative selectivity up to $80 \%$ ). Results suggest that mesitylene formation takes place via isophorones instead of via direct dehydration-cyclization of phorones. However, acetic acid and isobutene are also formed ( $\beta$-scission of $\mathrm{C} 6$ compounds). This side reaction has two negative effects: (i) competition with the target reaction decreasing mesitylene yield; and (ii) formation of intermediate acetate species involved in the acetic acid formation, leading to fast deactivation, especially at initial reaction times. This last point was confirmed by DRIFTS analysis. Co-feeding of molecular hydrogen was considered for improving the catalytic stability and the selectivity to aromatics. In fact, the catalytic activity of MCM-41 and BEA is enhanced, with mesitylene yields around 60 and $100 \%$ higher with regard to inert operating conditions, respectively. However, supplying $\mathrm{H}_{2}$ entails a drop on the catalytic dehydration activity due to its interaction with active sites. This fact implies lower relative selectivity to mesitylene regarding all the C9 compounds (ca. 50\%). Otherwise, the absolute selectivity to mesitylene is improved since the C6 $\beta$ scission reaction is largely hindered by the presence of $\mathrm{H}_{2}$.

\section{Introduction}

Polymethylbenzenes (PMBs) are a high reactive family of benzene derivatives, being widely used as precursors for the production of more complex chemicals and intermediate species. ${ }^{1-4}$ In general terms, the upgrading processes of PMBs are based on alkylation and acylation reactions using FriedelCrafts catalysts. ${ }^{5,6}$ Several PMBs can be obtained from extracted reformate of nine-carbon compounds by superfractionation (e.g., pseudocumene, mesitylene, hemimellitene, indane, etc.), but only the pseudocumene can be separated with high purity, due to close boiling point of the rest of PMBs and other species obtained during the reformate (e.g., mesitylene and 2ethyltoluene). ${ }^{7}$ Thus, the pseudocumene is typically used as starting material for the production of the other trimethylbenzenes, hemimellitene and mesitylene, by isomerization. ${ }^{8}$

Among PMBs, mesitylene highlights because of its high reactivity for electrophilic reactions. It has many different industrial uses, mainly as building block for the production of other chemicals, such as a no colouring antioxidant and thermal

Catalysis, Reactors and Control Research Group (CRC), Department of Chemical and Environmental engineering, University of Oviedo, 33006, Spain

Corresponding author email: sordonez@uniovi.es

† Dr. J. Quesada, Dr. L. Faba, Dr. E. Díaz, Prof. S. Ordóñez

Electronic Supplementary Information (ESI) available: [Diffusional resistances to acetone transfer, Table S1-S2. Table S3-S8: Disaggregated selectivities of the compounds lumped under the C6 and C9 pools. Table S9: Relative selectivities of isophorones and mesitylene. Figure S1-S3: $\mathrm{NH}_{3}$ evolved in TPD-MS analysis of $\mathrm{NH}_{4}{ }^{+}$ exchanged commercial zeolites. Figure S4: DRIFT spectra of the band linked to VC-C and $\mathrm{\delta} C H \mathrm{H}$ of mesitylene]. See DOI: 10.1039/x0xx00000x stabilizer for plastics, rubber, adhesives, and waxes, characterized by its low oral toxicity. 7,9 The formylation of mesitylene using super-acid catalysts (e.g., $\mathrm{HF}^{-\mathrm{BF}_{3}}$ ) produces mesitaldehyde, which is used as intermediate in the synthesis of plant growth regulators. ${ }^{10}$ The mesitylene oxidation allows the obtaining of 1,3,5-benzenetricarboxylic acid and other intermediate acids. ${ }^{11}$ Furthermore, the mesitylene is also utilized for the production of a dye intermediate via nitration (2,4,6-trimethylaniline). ${ }^{12}$ In the field of the pollution mitigation, mesitylene can be used to scavenge contaminant nitric oxide from an effluent gas stream. ${ }^{13}$

Mesitylene can be formed through the self-condensation of acetone catalysed following the same reaction pathway by both basic and acid heterogeneous catalysis. ${ }^{14,15}$ This route allows obtaining mesitylene without the co-production of any other isomers or compounds with similar boiling point, being a very interesting advantage for selectively obtaining mesitylene without producing other PMBs. The different reaction pathways in the acetone upgrading by aldol condensation are shown in Scheme 1. It is worth mentioning that most of the studies dealing with this reaction used acid-basic catalysts with a clear basic character (e.g., $\mathrm{MgO}, \mathrm{Mg}-\mathrm{Zr}$ and $\mathrm{Mg}$-Al mixed oxides, $\left.\mathrm{TiO}_{2}\right)^{14,16-18}$ in which mesitylene can be produced from phorones and isophorones, by dehydration-cyclization and dehydration, respectively. Whereas the beginning of the former route is promoted by acid-basic pair sites (through proton abstraction), the latter one is catalysed by acid sites through $E_{2}$ mechanism. ${ }^{16}$ Previous works demonstrated that the formation of isophorones over mesitylene is favoured with acid-basic catalysts. ${ }^{16,19}$ These results suggest that acetone aldol condensation catalysed by solid acids should improve 


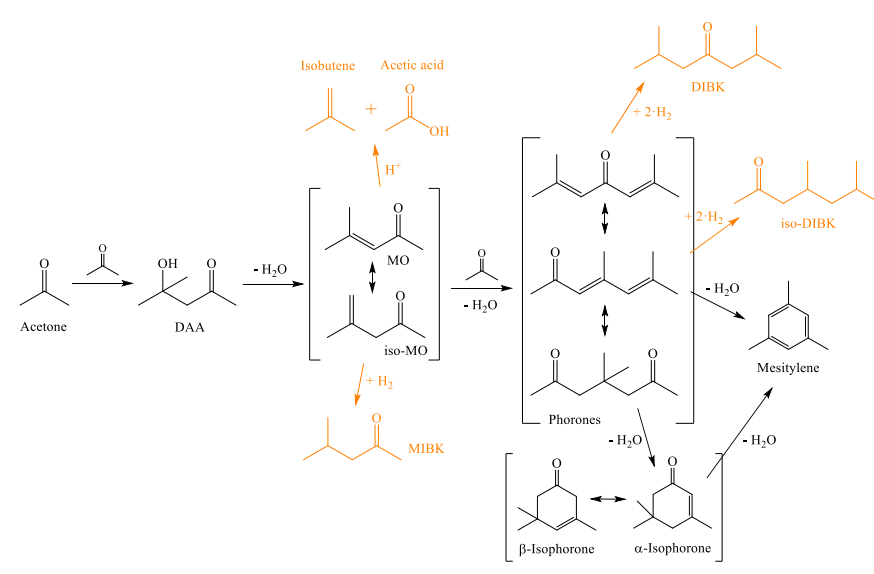

Scheme 1. Overall mechanism for acetone conversion by self-condensation. (DAA: diacetone alcohol; MO: mesityl oxide; MIBK: methyl isobutyl ketone; DIBK: diisobutyl ketone). Colours: black (main reaction pathways); orange (side reactions).

isophorone dehydration, yielding higher mesitylene/isophorone formation ratios comparing with basic heterogeneous catalysis.

The use of acetone as starting material for the production of mesitylene is of the highest interest. Large amounts of acetone are currently produced as by-product in the synthesis of phenol by the cumene oxidation process. ${ }^{20}$ Moreover, acetone can be obtained from biomass through the ABE (acetone-butanolethanol) fermentation or pyrolysis processes using the lignocellulosic fraction. ${ }^{21,22}$ Thus, the use of this bio-based acetone as building block is a new environmental incentive for the development of this mesitylene production route.

Different structured materials have been proved as highly efficient catalysts for renewable feedstock into bio-based fuels and chemicals, highlighting the aluminosilicates. ${ }^{23-25}$ Likewise, the excellent chemical and thermal stability of these materials enables their application to catalysis that, in turn, allows studying complex chemical reactions via both experimental and theoretical approaches because of the surface chemistry homogeneity conferred by the structure (i.e., well-known active sites). ${ }^{26,27}$

In this light, herein, different structured aluminosilicates were used as catalysts in the gas-phase acetone self-condensation, with the aim of improving the production of mesitylene as well as determining how the acidity and material morphology of aluminosilicates affect the performance of the reaction. The materials tested were: (i) a mesoporous one with MCM-41 structure; and (ii) three microporous: two MFI zeolites with different Si/Al ratio, and a BEA zeolite. The influence of $\mathrm{H}_{2} \mathrm{CO}-$ feeding in the reaction performance was also tested, focusing on the reduction of the catalytic deactivation. Although aluminosilicates lack the metallic phase usually needed to activate the hydrogen molecule, previous studies with these materials prove its ability to activate molecular hydrogen (e.g., catalysing reactions as olefin hydrogenation). ${ }^{28,29}$ The interaction of $\mathrm{H}_{2}$ with non-metallic sites of the studied materials might imply different catalytic activity and stability comparing with working in inert conditions. ${ }^{15,30}$ The analysis of the gasphase effluent by gas chromatography was complemented with infrared experiments for analysing the evolution of the solid surface (species adsorbed).

\section{Experimental}

\section{Materials and active sites (protons) determination}

Commercial aluminosilicates have been used as catalysts in this study: mesoporous with MCM-41 structure, $\mathrm{H}^{+}-\mathrm{Al}-\mathrm{MCM}-41$, (Aldrich, Si/Al = 39.5); NH4+-MFI (Zeolyst, $\mathrm{Si} / \mathrm{Al}=11.5$ ); $\mathrm{NH}^{+}$-MFI (Zeolyst, Si/Al $=25.0$ ); and $\mathrm{NH}^{+}$-BEA (Zeolyst, $\mathrm{Si} / \mathrm{Al}=12.5) . \mathrm{NH}^{+}$-exchanged zeolites were thermally treated to desorb $\mathrm{NH}_{3}$, thus leading to active catalysts (i.e., protonated forms, $\mathrm{H}^{+}-\mathrm{MFI}$ and $\mathrm{H}^{+}-\mathrm{BEA}$ ). Therefore, prior to performing catalytic experiments, materials were treated in airflow $\left(40 \mathrm{~cm}^{3} \mathrm{~g}^{-1} \mathrm{~min}^{-1}\right)$ from 293 to $823 \mathrm{~K}$ at $1.5 \mathrm{~K} \mathrm{~min}^{-1}$ of heating rate, keeping the final temperature for $5 \mathrm{~h}$. This thermal treatment was also carried out in the case of the Al-MCM-41 to follow the same procedure for all the materials, although it is originally in its protonated form (i.e., $\mathrm{H}^{+}-\mathrm{Al}-\mathrm{MCM}-41$ ). Materials' powders were pelletized by pressing into wafers at 92.5 MPa for $2 \mathrm{~min}$, crushed, and sieved to bring $250-355 \mu \mathrm{m}$ aggregates. Samples are named from now on as: MCM-41 ( $\left.\mathrm{H}^{+}-\mathrm{Al}-\mathrm{MCM}-41\right)$, $\mathrm{MFI1}\left(\mathrm{H}^{+}-\mathrm{MFI}, \mathrm{Si} / \mathrm{Al}=11.5\right), \mathrm{MFI} 2\left(\mathrm{H}^{+}-\mathrm{MFI}, \mathrm{Si} / \mathrm{Al}=25.0\right)$, and BEA $\left(\mathrm{H}^{+}-\mathrm{BEA}\right)$.

The concentration of acid sites, in the case of the $\mathrm{NH}_{4}{ }^{+}$-exchanged commercial materials (i.e., $\mathrm{NH}_{4}{ }^{+}-\mathrm{MFI}$ and $\mathrm{NH}_{4}{ }^{+}-\mathrm{BEA}$ ), was quantified by temperature-programmed desorption (TPD) following the evolution of the $\mathrm{NH}_{3}$ desorbed during its thermal treatment (protonation) by mass spectrometry (MS). The use of this technique to the particular analysis of Bronsted acids is supported by the literature, as a good substitute of pyridine titration. ${ }^{15}$ Analyses were carried out proceeding with the same thermal treatment method cited for the protonation of $\mathrm{NH}_{4}{ }^{+}$-zeolites in the above paragraph. The TPD-MS equipment consists of a Micromeritcs AutoChem II 2920 unit coupled to a Pfeiffer Vacuum Omnistar Prisma mass spectrometer.

\section{Catalytic activity studies}

Reaction experiments were carried out at $573 \mathrm{~K}$ and $101.3 \mathrm{kPa}$ using a U-shaped packed bed reactor made of quartz $(8.0 \mathrm{~mm}$ i.d.). The catalyst mass $(100 \mathrm{mg})$ was placed at the top of a quartz plug inside the reactor, in turn, introduced in a furnace. The temperature is measured and controlled using a thermocouple located near the sample. Samples used in each test were pre-treated in flowing $\mathrm{He}$ $\left(200 \mathrm{~cm}^{3} \mathrm{~g}^{-1} \mathrm{~min}^{-1}\right.$ ) at $623 \mathrm{~K}$ during $1 \mathrm{~h}$ prior to the reaction. Afterwards, the temperature was cooled down to the reaction one, keeping the He flow. Acetone $(A)$ from VWR ( $\geq 99.9 \%$ ) was injected into the He flow $\left(200 \mathrm{~cm}^{3} \mathrm{~g}^{-1} \mathrm{~min}^{-1}\right.$ ) using a liquid syringe-pump $\left(0.017 \mathrm{~cm}^{3} \mathrm{~min}^{-1}\right.$; resulting in $20 \mathrm{~mol} \%$ of acetone in the gas-phase), and sudden vaporized in a transfer line heated at $523 \mathrm{~K}$. The weight hourly space velocity (WHSV) was $7.8 \mathrm{~h}^{-1}$. Reactor outgoing gases were analysed by gas chromatography (HP 6890Plus) equipped with a flame ionization detector (FID), using a TRB-5MS capillary column 
( $30 \mathrm{~m}, 0.25 \mathrm{~mm}, 0.25 \mu \mathrm{m}$ ). Both retention times and response factors of the acetone and reaction products were determined using commercial standards. External and internal diffusional resistances were evaluated for each material based on experimental data, being the explanation of the procedure and calculations included in the Supplementary Information (SI; summarized in Table S1-S2).

In the case of the reaction experiments in presence of $\mathrm{H}_{2}$, the same procedure was used but with $20 \mathrm{vol} \% \mathrm{H}_{2} / \mathrm{He}$ as flowing gas $\left(200 \mathrm{~cm}^{3} \mathrm{~g}^{-1} \mathrm{~min}^{-1}\right)$, instead of $\mathrm{He}$, during both pre-treatment and reaction tests.

\section{Catalytic deactivation assessment}

The evaluation of the catalytic stability loss was carried out working in both absence and presence of $\mathrm{H}_{2}$ by modelling the catalyst deactivation through a power-law kinetic expression Eq. (1):

$$
r_{d}=-d a / d t=k_{d}[A]^{\alpha} a^{d}
$$

being: $r_{d}$, the deactivation rate; $a$, the catalyst activity; $t$, the timeon-stream (TOS); $d$, the deactivation rate order; $k_{d}$, the deactivation rate constant; and $\alpha$, the exponent that specifies the dependence of the deactivation rate on the concentration of acetone $([A])$ that affects catalyst deactivation. After analysing different approaches, and according to the fitting results, this model has been simplified considering (i) first-order deactivation kinetic $(d=1)$; and (ii) the independence of the deactivation rate on the $[A](\alpha=0)$ because of differential conditions of operation $([A]$ almost constant with the reaction time due to the low acetone conversion. See section 3 ); and taking into account the relation between the acetone reaction rate ( $r$; defined as the molar amount of acetone converted per unit of mass of catalyst and time) and the catalytic activity (Eq. (2)), the acetone reaction rate can be described as follows Eq. (3)

$$
\begin{gathered}
r=r_{0} a \\
r=r_{0} \exp \left(-k_{d} t\right)
\end{gathered}
$$

where $r_{0}$ is the acetone reaction rate at zero time (i.e., absence of catalytic deactivation). In turn, the evolution of the acetone conversion $(x)$ can be represented in terms of the deactivation rate constant (Eq. (4)). This mathematical expression is a simplification of the accurate resolution of the catalytic deactivation model by considering the relationship between reaction rate and conversion through the space velocity (SV), which is valid whenever differential reaction conditions applied (Eq. (5)).

$$
\begin{gathered}
x=x_{0} \exp \left(-k_{d} t\right) \\
r=x S V
\end{gathered}
$$

being $x_{0}$ the acetone conversion at zero time.

The formation rate of the product $i\left(r_{i}\right)$, defined as the molar quantity of compound $i$ generated per catalyst weight and time, was calculated using the Eq. (6), being $\varphi_{i}$ the selectivity to product $i$ determined using Eq. (7).

$$
\begin{gathered}
r_{i}=\left(\frac{\text { number of carbons of molecule } A}{\text { number of carbons of molecule } i}\right) r \varphi_{i} \\
\varphi_{i}=\frac{\text { mol of carbon of } A \text { converted to compound } i}{\text { total mol of carbon of A converted }}
\end{gathered}
$$

\section{Infrared analyses during reaction}

In situ diffuse reflectance infrared Fourier transform spectroscopy (DRIFTS) experiments were carried out for the gas-phase acetone self-condensation at $573 \mathrm{~K}$ both in inert conditions and in presence of $\mathrm{H}_{2}$. Spectra were acquired using a Thermo Nicolet Nexus FT-IR equipped with the Smart Collector accessory and a mercurycadmium-telluride (MCT) detector. Catalyst samples were pretreated at $623 \mathrm{~K}$ for $1 \mathrm{~h}$ in a He flow $\left(500 \mathrm{~cm}^{3} \mathrm{~g}^{-1} \mathrm{~min}^{-1}\right)$, or in flowing 20 vol. $\% \mathrm{H}_{2} / \mathrm{He}\left(500 \mathrm{~cm}^{3} \mathrm{~g}^{-1} \mathrm{~min}^{-1}\right)$ when $\mathrm{H}_{2}$ co-feeding experiments, before performing analyses. The gas stream $\left(500 \mathrm{~cm}^{3} \mathrm{~g}^{-1} \mathrm{~min}^{-1}\right.$ of $\mathrm{He}$ or $20 \mathrm{vol} . \% \mathrm{H}_{2} / \mathrm{He}$ for inert or reducing conditions, respectively) was saturated with acetone by the use of a bubbler kept at constant temperature (external cooling at $c a .273 \mathrm{~K}$ ), before entering inside the catalytic chamber. The $\mathrm{KBr}$ standard background was subtracted from recorded signals. The Kubelka-Munk theory was utilized to convert signals to final spectra, thus enabling semi-quantitative analyses and comparison between spectra.

\section{Results and Discussion}

\section{Acetone self-condensation in inert atmosphere}

Different commercial aluminosilicates were used in this study, after an activation treatment (to obtain their protonated form) but without further modification of their chemical properties. The proton concentration (number of protons per weight of catalyst) is the key parameter to analyse the acetone reaction rate, since acetone, with a kinetic diameter of $0.48 \mathrm{~nm}$, can enter inside the channels of all the materials tested, as it can be noticed by comparing this value with the pore-limiting diameter $\left(d_{\mathrm{PL}}\right)$ of each tested material (Table 1). ${ }^{31,32}$ The proton concentration of fresh materials is summarized in Table 1, while the TPD-MS profiles obtained for $\mathrm{NH}_{3}$ desorption used for their quantification are included in the $\mathrm{SI}$ (Figure S1-S3). The value previously reported in the literature is considered for the proton counting of the MCM- $41,{ }^{15}$ since it is commercialized in its protonated state $\left(\mathrm{NH}_{3}\right.$ desorption cannot be measured).

Conversion evolutions show that all the materials undertook significant deactivation, being more remarkable below $2 \mathrm{~h}$ (Figure 1). Results obtained from the evaluation of the catalytic deactivation are summarized in Table 2. Significant conversion decreases were noticed after $\sim 6 \mathrm{~h}, 45.7,56.3,77.9$, and $65.7 \%$ with MCM-41, MFI1, $\mathrm{MFI}$, and BEA, respectively. This fact was in agreement with previous works, ${ }^{33,34}$ considering this behaviour as a drawback of acid sites in $\mathrm{C}-\mathrm{C}$ bond forming reactions, due to the higher stabilization and the strong binding of the molecules adsorbed. Consequently,

Table 1. Main data of the aluminosilicates samples.

\begin{tabular}{ccccc}
\hline Material & Si/Al & $\mathbf{H}^{+} / \mathrm{Al}^{\mathrm{a}}$ & {$\left[\mathrm{H}^{+}\right]^{\mathrm{a}}\left(\mathbf{H}^{+} \mathbf{g}^{-1}\right), \mathbf{1 0}^{-19}$} & $\mathbf{d}_{\mathrm{PL}^{\mathrm{c}}}(\mathbf{n m})$ \\
\hline MCM-41 & 39.5 & $0.42^{\mathrm{b}}$ & $6.31^{\mathrm{b}}$ & $2.50^{\mathrm{d}}$ \\
MFI1 & 11.5 & 0.20 & 9.92 & 0.50 \\
MFI2 & 25.0 & 0.12 & 2.86 & 0.50 \\
BEA & 12.5 & 0.26 & 11.85 & 0.67 \\
\hline
\end{tabular}

a From the quantity of $\mathrm{NH}_{3}$ desorbed from $\mathrm{NH}_{4}{ }^{+}$-exchanged initial zeolites (Figure S1-S3).

${ }^{b}$ From 2,6-di-tert-butylpyridine titration during acetone condensation at $473 \mathrm{~K} .^{15}$

c Pore-limiting diameter. ${ }^{19}$

d Pore-limiting diameter provided by the manufacturer (Aldrich). 


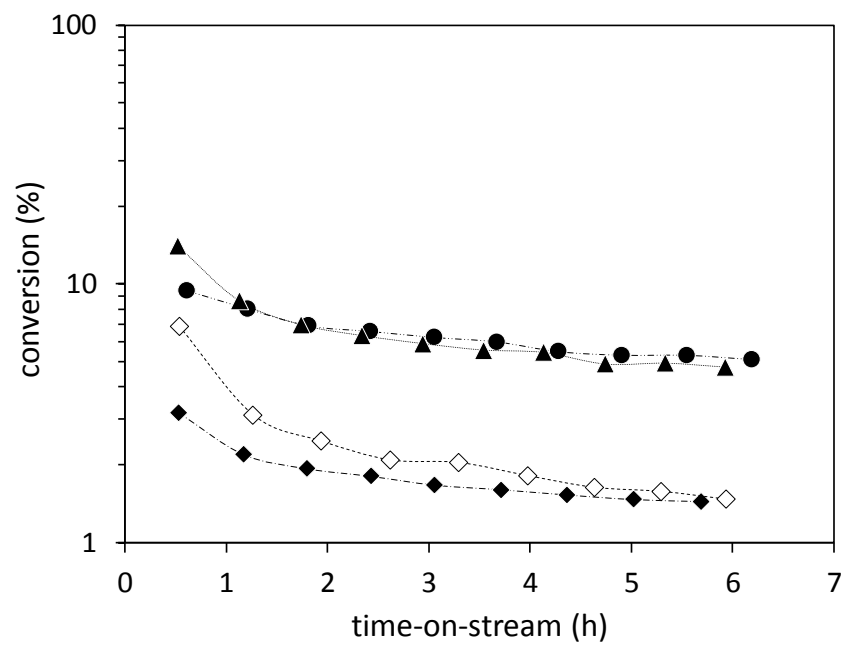

Figure 1. Acetone conversion evolution with the time-on-stream in the gas-phase acetone self-condensation at $573 \mathrm{~K}\left(\mathrm{WHSV}=7.8 \mathrm{~h}^{-1}\right)$. Symbols: - MCM-41, MFI1, $\diamond \mathrm{MFI}$, and $\Delta$ BEA. Lines are meant to guide the eye.

this fact results in pore and active sites blockage leading to deactivation. Moreover, in the case of zeolites, the molecule confinement inside the channels implies Van der Waals forces of the surrounding atoms of the zeolite framework, favouring the stabilization of molecules with similar diameter that the void one. ${ }^{15}$

Studied catalysts present different activities at initial times. Values of $9.4,3.2,6.8$, and $14.0 \%$ are reached in the first measurement ( 0.6 h), with MCM-41, MFI1, MFI2, and BEA, respectively. Conversions estimated at zero time are $11.1,4.4,9.3$, and $18.1 \%$ for MCM-41, MFI1, MFI2, and BEA, respectively. On this basis, differential reaction conditions can be assumed and, therefore, Eq. (4) used to assess the catalytic deactivation. During the first $2 \mathrm{~h}$, the conversion achieved with BEA decreases with higher rate than that observed with the MCM-41 ( $k_{d}$ of 0.578 and $0.262 \mathrm{~h}^{-1}$ with BEA and MCM-41, respectively). Thereafter, the results obtained with these two materials show similar values for all the measurements. However, the order of the MCM-41 and BEA are interchanged regarding acetone conversion, but reaching rather similar values (23.7 $10^{-20}$ and $20.610^{-20} \mathrm{mmol} \mathrm{H}^{+-1} \mathrm{~h}^{-1}$ with MCM-41 and BEA, respectively). This fact seems to reveal that $M C M-41$ sites are more active than those of BEA. Indeed, MCM-41 circumvents relevant confinement effects concomitant to the use of zeolites (i.e., Van der Waals forces in the surroundings of protons inside channels).

Confinement promotes the stabilization of adsorbed acetone or subsequent intermediates by synergistic effects of protons (Brønsted acid sites) and Al-atoms (Lewis acid sites), ${ }^{35}$ implying active site blockage or lower turnover frequency (TOF). In turn, internal diffusional constraints limit the reaction in all the cases, being this effect the one that governs the extent of the reaction when using zeolites due to the low pore size (supported by the assessment of the external and internal diffusional resistances to acetone transfer, included in $\mathbf{S I}$ ). On this basis, it can be stated the different framework structure as the explanation of the lower activity of the BEA sites comparing with the MCM-41 ones. ${ }^{15}$ The use of mesoporous MCM-41 has been considered to deal with large molecules whose diffusion was strongly hindered in zeolites' micropores. ${ }^{36}$

Whereas the acetone reaction rate at zero time per proton remains the lowest for the MFI1 comparing to conversion values, unexpectedly, it is the highest for the MFI2 $\left(44.110^{-20} \mathrm{mmol} \mathrm{H}^{+-1} \mathrm{~h}^{-1}\right.$; $86 \%$ higher than the second value corresponding to MCM-41). In view of these results and the complexity of the reaction (Scheme 1), it is suggested that the huge difference observed between acetone conversion and acetone reaction rate at zero time per proton with the MFI2 comparing with the rest of the materials is due to higher extent of side-reaction(s) with the MFI2. Despite the different concentration of protons and initial activity between MFI1 and MFI2, both zeolites achieve similar conversions over $4.2 \mathrm{~h}$. The first-order deactivation rate constant for the $\mathrm{MFI} 2$ is $85 \%$ higher than the corresponding one to MFI1 below $2 \mathrm{~h}\left(0.069\right.$ and $0.113 \mathrm{~h}^{-1}$ with MFI1 and $\mathrm{MFI} 2$, respectively), otherwise it is reduced to $64 \%$ higher over $2 \mathrm{~h}$ ( 0.397 and $0.733 \mathrm{~h}^{-1}$ with MFI1 and MFI2, respectively). According to the lower strength of active sites observed for the MFI2 (in comparison to MFI1), it would be expected that deactivation effects were lower in the case of MFI2. However, experimental results reject this hypothesis, suggesting that the strength of acid sites is not the key parameter that conditions the stability in these materials. Thus, the faster deactivation of MFI2 comparing with MFI1 below $2 \mathrm{~h}$ is mainly due to strongly adsorbed intermediates of undesired reaction(s) that seem to be much more relevant with the MFI2.

In the case of the MFI1, the acetone reaction rate at zero time per proton achieved is much lower than that reached with $\mathrm{BEA}$, although its proton concentration is similar $\left(9.9210^{19}\right.$ and $11.8510^{19} \mathrm{H}^{+} \mathrm{g}^{-1}$ for MFI1 and BEA, respectively). In this context, it is suggested that this

Table 2. Results obtained from the assessment of the catalytic deactivation in the gas-phase acetone self-condensation at $573 \mathrm{~K}$ in both absence and presence of $\mathrm{H}_{2}\left(\mathrm{WHSV}=7.8 \mathrm{~h}^{-1}\right)$.

\begin{tabular}{|c|c|c|c|c|}
\hline \multirow[t]{2}{*}{ Material } & \multicolumn{2}{|c|}{$\mathrm{k}_{\mathrm{d}}\left(\mathrm{h}^{-1}\right),\left[R^{2}\right]^{\mathrm{a}}$} & \multirow[t]{2}{*}{$x_{0}(\%)$} & \multirow[t]{2}{*}{$\mathrm{r}_{0} /\left[\mathrm{H}^{+}\right]\left(\mathrm{mmol} \mathrm{H}^{+-1} \mathrm{~h}^{-1}\right), 10^{20}$} \\
\hline & TOS $<2 \mathrm{~h}$ & TOS $>2 \mathrm{~h}$ & & \\
\hline MCM-41 & $0.262,[0.998]$ & $0.068,[0.940]$ & 11.1 & 23.7 \\
\hline MCM-41* & $0.239,[0.943]$ & $0.093,[0.996]$ & 16.7 & 35.7 \\
\hline MFI1 & $0.397,[0.930]$ & $0.069,[0.962]$ & 4.4 & 5.9 \\
\hline $\mathrm{MFI} 2$ & $0.733,[0.923]$ & $0.113,[0.972]$ & 9.3 & 44.1 \\
\hline BEA & $0.578,[0.951]$ & $0.079,[0.950]$ & 18.1 & 20.6 \\
\hline BEA* $^{*}$ & $0.471,[0.890]$ & $0.063,[0.932]$ & 26.0 & 29.7 \\
\hline
\end{tabular}

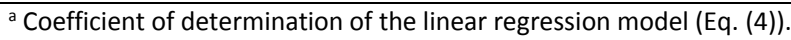

$* \mathrm{H}_{2}$ co-feeding conditions. 
different behaviour is due to MFI size constraints comparing with BEA framework. The estimated size of the $\mathrm{H}$-bonded and $\mathrm{C}-\mathrm{C}$ bond formation transition states of acetone, determined by density functional theory (DFT), have been reported as 0.581 and $0.626 \mathrm{~nm}$, respectively..$^{15}$ Based on this, although acetone can enter inside the MFI framework (channels: $0.51 \times 0.55$ and $0.53 \times 0.56 \mathrm{~nm}$; acetone kinetic diameter: $0.48 \mathrm{~nm}$ ), it is only able to be stabilized inside channels by Van der Waals forces without binding protons (i.e., no formation of the $\mathrm{H}$-bonded acetone transition state). ${ }^{31,32}$ However, both $\mathrm{H}$-bonded and $\mathrm{C}-\mathrm{C}$ bond formation transition states could be catalysed by the protons located inside the intersection between sinusoidal and straight channels of MFI $(0.8 \mathrm{~nm}),{ }^{37}$ but none reaction product different from the $\mathrm{C} 6 \beta$-scission ones can diffuse outside its framework throughout the channels because of size limitations. Likewise, BEA voids allow to yield even the $\mathrm{C}-\mathrm{C}$ bond formation transition state of acetone and diffusion of resulting products (i.e., C6) outside its framework through the channels, therefore all protons of the BEA zeolite are active for the conversion of acetone. ${ }^{31}$ On the other hand, only protons existing on the external surface and in the intersection between channels of the MFI1 framework show catalytic activity for the acetone self-condensation, hence implying lower acetone reaction rate per proton in spite of similar proton concentration regarding the BEA zeolite.

Concerning the activity in terms of selectivity, values determined for the desired reaction pathways (black colour part in Scheme 1) were grouped under six and nine carbon compound pools (C6-pool and C9pool) to make easier the catalytic activity and stability analyses. Disaggregated selectivities of both C6 and C9 pools obtained with each material are summarized in Table S3-S8 of the SI.

The evolutions of the selectivity to mesitylene obtained with each material during the reaction time are shown in Figure 2 . In the case of the MFI1, it reaches $4.4 \%$ after $\sim 5.8 \mathrm{~h}$ of time-on-stream $(1.8 \%$ at initial times), and its formation is favoured comparing to the rest of species that composed the C9-pool (Table S4). Results obtained with the MCM-41 and BEA are significantly higher, achieving values of 14.8 and $9.3 \%$ at initial times. Moreover, the selectivity to mesitylene

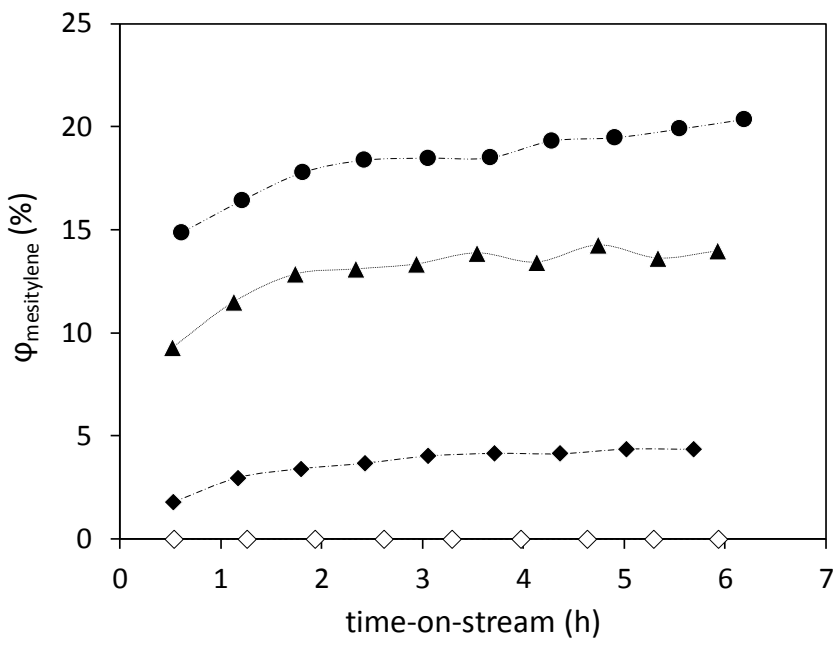

Figure 2. Evolution of the selectivity to mesitylene with the time-on-stream in the gas-phase acetone self-condensation at $573 \mathrm{~K}$ $\left(\mathrm{WHSV}=7.8 \mathrm{~h}^{-1}\right)$. Symbols: $\mathrm{MCM}-41, \diamond \mathrm{MFI} 1, \diamond \mathrm{MFI}$, and $\boldsymbol{\Delta} \mathrm{BEA}$. Lines are meant to guide the eye. continuously increases with the reaction time, when using the MCM41 , reaching $20.4 \%$ at $\sim 6.1 \mathrm{~h}$ (37.8\% of increase regarding initial times). In the case of the BEA, the mesitylene selectivity raises up to $\sim 3.1 \mathrm{~h}$ and, after that, it is kept at $\sim 14 \%$ (50.5\% of increase comparing to initial times). It could be expected that, as well as deactivation takes place, the selective formation of larger molecules (generated by consecutive reaction cycles) is hindered or, even, suppressed. However, the selectivity to mesitylene increases with the time-on-stream. This fact is due to a gradual increase of the selectivity to the main pathway (black colour in Scheme 1) at the cost of the $\mathrm{C} 6 \beta$-scission side-reaction that produces acetic acid and isobutene, improving the relative formation of $\mathrm{C} 6$ and $\mathrm{C} 9$ species.

The c9-share of mesitylene reached are outstanding. Thus, the mesitylene/C9 selectivity ratios, shown in Figure 3, are always higher than 0.70 in all the cases, keeping at constant values of $0.78,0.79$, and 0.85 above $1.1 \mathrm{~h}$ with MCM-41, MFI1, and BEA, respectively. Therefore, it can be stated that acid-catalysed acetone self-condensation allows obtaining mesitylene in a selective way with regard to the rest of the C9 compounds. Furthermore, it is worth mentioning that the MFI2 does not catalysed the mesitylene formation, in contrast to the other materials. This fact is also noticed by DRIFTS analyses (Figure S4), where the absorption band within $1400-1500 \mathrm{~cm}^{-1}$ related to $\mathrm{C}-\mathrm{C}$ stretching $(\mathrm{VC}-\mathrm{C}$ ) and $\mathrm{CHH}$ bending $(\delta \mathrm{CHH})$ vibration modes of mesitylene $\left(\sim 1439\right.$ and $\sim 1470 \mathrm{~cm}^{-1}$, respectively ${ }^{38}$ ) is not observed using the MFI2, whereas it arises for the other materials (slightly increasing with the reaction time after $4 \mathrm{~h}$ ). In fact, with the MFI2, the selectivity to the C9-pool is as low as $0.5 \%$, in the best of cases, and being only composed of isophorones (Table S5).

In view of this, the acid-catalysed acetone self-condensation yields mesitylene via isophorones dehydration, being negligible the routes involving dehydration-cyclization of phorones. This hypothesis is supported by a previous work that used a basic catalyst ( $\mathrm{Mg}$-Zr mixed oxides), proposing the promotion of isophorone dehydration to mesitylene by the acid sites of this mixed oxides. ${ }^{16}$ Nevertheless, the

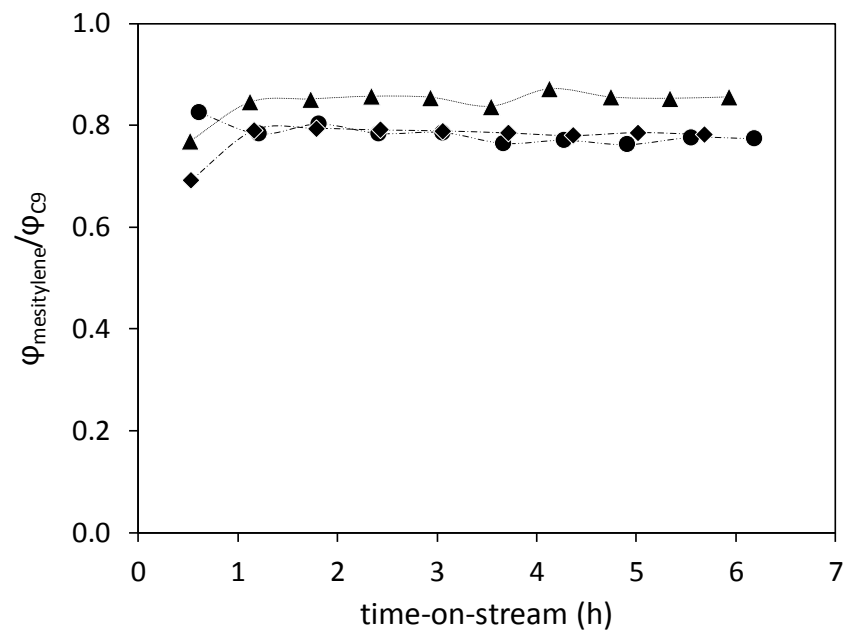

Figure 3. Evolution of the mesitylene/C9-pool selectivity ratio with the time-on-stream in the gas-phase acetone self-condensation at $573 \mathrm{~K}$ $\left(\mathrm{WHSV}=7.8 \mathrm{~h}^{-1}\right)$. Symbols: $\mathrm{MCM}-41, \bullet \mathrm{MFI}$, and $\boldsymbol{\Delta}$ BEA. Lines are meant to guide the eye. 
selective formation of mesitylene cannot be accomplished when using heterogeneous catalysis without acid sites, being the mesitylene/C9 selectivity ratio much lower than those values achieved here with solid acids (i.e., MCM-41, MFI1 and BEA). This fact is due to the lower dehydration capacity of basic catalysts, being the isophorones the main compound formed among C9 species. ${ }^{16-18}$ Indeed, the isophorones/C9-pool selectivity ratio reached $90 \%$ with a Mg-Al mixed oxide catalyst. ${ }^{19}$ Furthermore, it is noted that the mesitylene/C9-pool selectivity ratio is kept at a constant value despite deactivation (Figure 3). This fact unveils two hints: (i) the active sites that catalyse both phorones-to-isophorones and isophorones-to-mesytilene consecutive steps are the same, since it is unlikely that different active sites deactivate in the same extent with time (i.e., keeping the mesitylene/C9-pool selectivity ratio in a steady value); and/or (ii) the stability loss is due to side-reaction(s), hence the active sites that catalyse the target reaction pathway (black colour part in Scheme 1) are not affected by deactivation at the reaction temperature tested ( $573 \mathrm{~K})$.

Diacetone alcohol is not detected in any measurement for all the materials tested. This result is in good agreement with the previous literature, being explained by the kinetic relevant character of the aldol condensation equilibrium, and the subsequent fast dehydration suffered when using acid catalysts (irreversible step, $E_{2}$ mechanism). ${ }^{39,40}$

The selectivity to the C6-pool, shown in Figure 4a, follows the same rising trend with all the materials tested. Indeed, initial C6 selectivities $(\sim 0.6 \mathrm{~h})$ of $8.0,11.1,2.0$, and $4.5 \%$, reach values of 20.0, $30.5,9.8$, and $22.9 \%$ after $\sim 6 \mathrm{~h}$, with MCM-41, MFI1, MFI2, and BEA, respectively. In turn, the selectivity to the C6-pool needs to be analysed together with the selectivity to acetic acid (shown in Figure $4 b$ ). This is due to the $\beta$-scission side-reaction of the C6-pool, resulting in the 1:1 stoichiometric formation of acetic acid and isobutene. Thus, the different ability of each material to favour the $\beta$-scission can be discerned by following the selectivity to acetic acid (or isobutene). The highest acetic acid selectivities are achieved with the MFI2 (31.9\% at initial times), while the values reached with the other aluminosilicates are similar $(24.9,26.8$, and $25.3 \%$ with MCM$41, M F I 1$, and BEA, respectively, at initial times).

Acetic acid reaction formation rates per proton and selectivity to acetic acid after correcting catalytic deactivation (i.e., at zero time; $\varphi_{0, \text { acetic acid }}$ were determined by extrapolation of the experimental data) are depicted in Figure 5. The low value of the formation rate for the MFI1 is in line with its low acetone reaction rate per proton, or acetone conversion, observed with this material (Table 2). The acetic acid reaction rate and selectivity at zero time reach the highest value with the MFI2 $\left(23.110^{-20} \mathrm{mmol} \mathrm{H}^{+-1} \mathrm{~h}^{-1}\right.$ and $34.9 \%$, respectively), much different comparing to the other catalysts (9.5 10-20 $2.710^{-20}, 8.810^{-20} \mathrm{mmol} \mathrm{H}^{+-1} \mathrm{~h}^{-1}$, and 26.6, 30.4, 28.5\% for MCM-41, MFI1, and BEA, respectively). The main difference between $\mathrm{MFI} 2$ and the rest of materials is due to the much lower acidity of the former $\left(2.8610^{19} \mathrm{H}^{+} \mathrm{g}^{-1}\right)$. In the case of MFI1 and BEA, similar selectivities might be related to the close proton concentration between them (9.92 $10^{19}$ and $\left.11.8510^{19} \mathrm{H}^{+} \mathrm{g}^{-1}\right)$. This is in agreement with a recent work of Herrmann and Iglesia, in which two likely reactions mechanisms are disclosed for this reaction. ${ }^{41}$ They state that the prevalent mechanism involves the formation of $\mathrm{C} 6$ enols

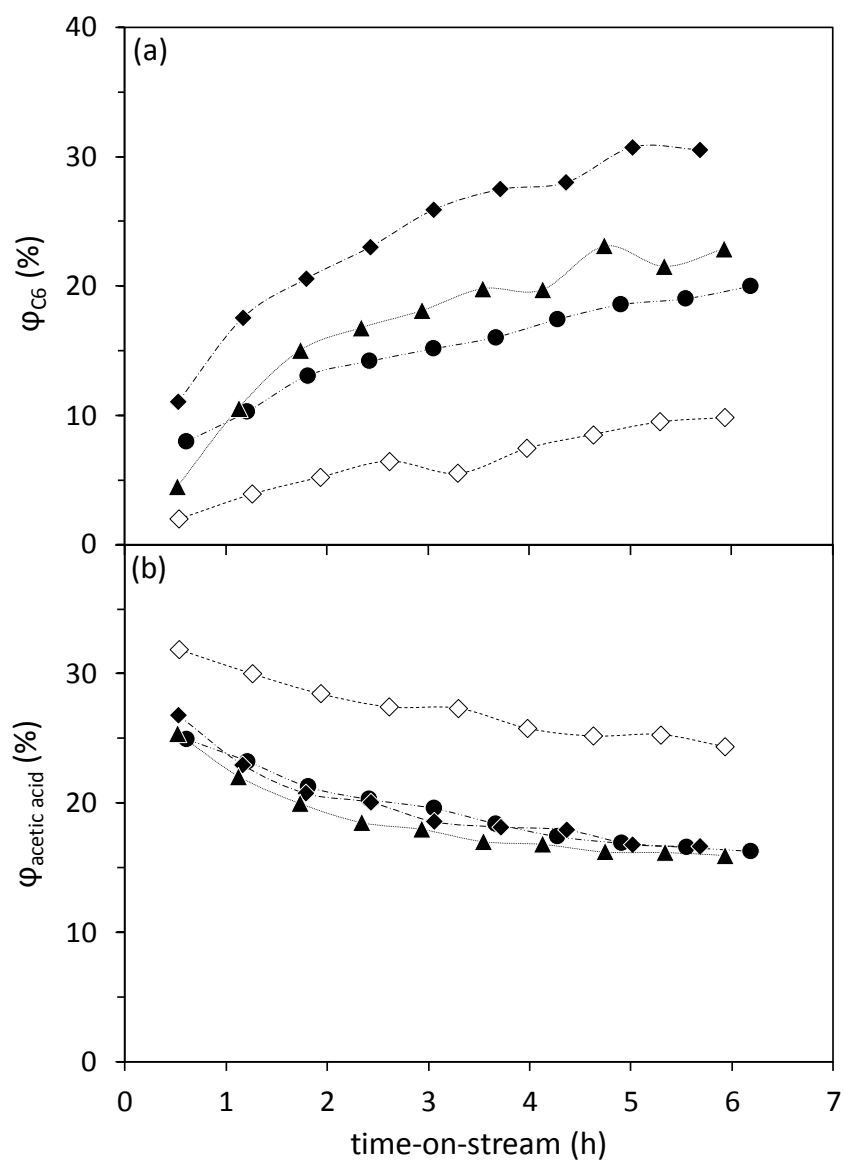

Figure 4. Evolution of the selectivity to (a) C6-pool and (b) acetic acid with the time-on-stream in the gas-phase acetone self-condensation at $573 \mathrm{~K}$ $\left(\mathrm{WHSV}=7.8 \mathrm{~h}^{-1}\right)$. Symbols: MCM-41, MFI1, $\diamond \mathrm{MFI}$, and $\triangle$ BEA. Lines are meant to guide the eye.

(from the C6-pool) on protons, which, subsequently, produce acetic acid and isobutene by radical-mediated pathways. According to them, the C6 $\beta$-scission selectivity increases as decreases the concentration of protons. In turn, although the MCM- 41 material owns different density of protons $\left(6.3110^{19} \mathrm{H}^{+} \mathrm{g}^{-1}\right.$; almost half of the $B E A$ one), the selectivity to acetic acid is basically the same as those achieved with both MFI1 and BEA, maybe, as a consequence of its different morphology. The MCM-41 structure consists of channels of around $2.5 \mathrm{~nm}$, an order of magnitude higher than those of the MFI and BEA zeolite structures. ${ }^{31}$ On this basis, it is suggested that, in the case of the MCM-41, the lack of confinement effects at the level of zeolites implies lower selectivity to $66 \beta$-scission reaction. Following the reaction time, the selectivity to acetic acid decreases with all the materials tested, reaching final values of $16.3,16.6,24.3$, and $16.0 \%$ (respective drops of $34.5,38.1,23.8$, and $36.8 \%$, with regard to initial times).

In view of the results, the decrease of the selectivity to acetic acid entails an increase of C6-pool and mesitylene (and, as a result, C9pool since the C9-share of mesitylene is kept almost constant). In other words, the $\mathrm{C} 6 \beta$-scission reaction is hindered along the timeon-stream hence the selectivity to $\mathrm{C} 6$ increases, favouring the subsequent $\mathrm{C}-\mathrm{C}$ bond formation that, ultimately, implies higher selectivity to mesitylene in spite of the lower acetone conversion. 


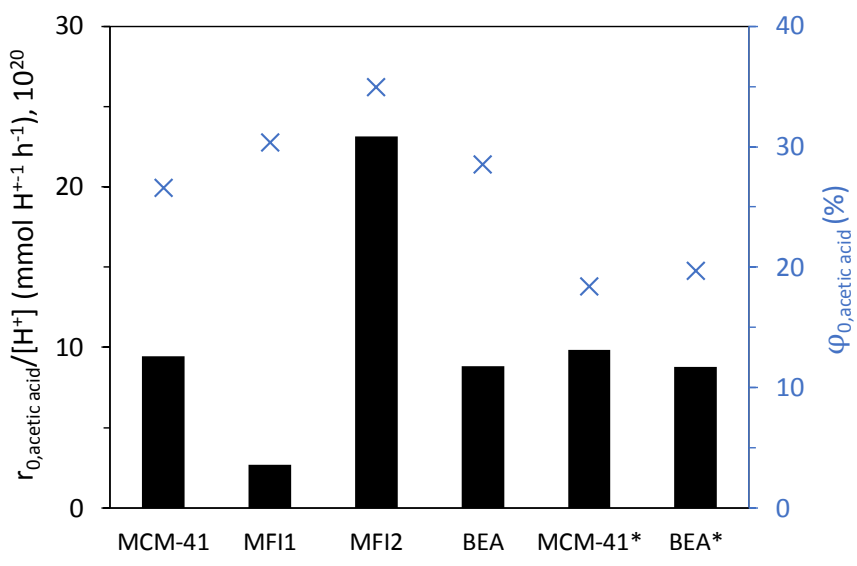

Figure 5. Acetic acid formation rate at zero time per proton and selectivity to acetic acid at zero time in the gas-phase acetone selfcondensation at $573 \mathrm{~K}$ on aluminosilicates (MCM-41, MFI, MFI2 and BEA) in inert conditions and in presence of $\mathrm{H}_{2}\left(\mathrm{WHSV}=7.8 \mathrm{~h}^{-1}\right)$. * Results corresponding to $\mathrm{H}_{2}$ co-feeding experiments.

This fact suggests that the active sites that promote the $\beta$-scission are quickly deactivated. DRIFTS analyses were carried out, at initial time $(0.5 \mathrm{~h})$ and once the activity is stable $(4 \mathrm{~h})$, to assess the evolution of the adsorbed species on the material surface over time. Three different bands can be noticed within the range of the $\mathrm{C}=\mathrm{O}$ stretching vibration mode $(\mathrm{VC}=0)$, shown in Figure $6 \mathrm{a}$. The broadest one ( $\mathrm{VC}=0$ others, within $1650-1700 \mathrm{~cm}^{-1}$ ) is associated with diacetone alcohol intermediate, mesityl oxide and isophorones. ${ }^{42}$ Although some of these compounds are undetected or determined in low amounts in the gas-phase (e.g., Table S4 -S5: C9 ketones with MFI1 and MFI2), they are likely to be formed and strongly adsorbed on the active sites at the reaction temperature without accomplishing desorption. ${ }^{43}$ The other two bands are quite near each other ( $\mathrm{VC}=\mathrm{O}$ acetone and $\mathrm{vC}=\mathrm{O}$ acetate), without a clear splitting in some cases, hence making hard the analysis. However, two distinct peaks are noticed, at $\sim 1726$ and $1736 \mathrm{~cm}^{-1}$ for $\mathrm{vC}=\mathrm{O}$ acetone and $\mathrm{vC}=\mathrm{O}$ acetate, respectively. ${ }^{44}$ The assigning of the $\mathrm{vC}=\mathrm{O}$ acetate band is also proved in Figure $6 \mathrm{~b}$ by the presence of the $\mathrm{C}-\mathrm{C}$ stretching vibration mode band of acetate (vC-C) at 750-840 $\mathrm{cm}^{-1} .44$ Furthermore, the intensities of the absorption bands increase with the reaction time, which implies higher saturation of the material surface and strong adsorption of the intermediates and compounds yielded. The acetate band becomes the most relevant one among the $v C=0$ bands after $4 \mathrm{~h}$. In this light, it is considered that these adsorbed acetates could be the cause of deactivation of the active sites, since the strong-adsorption of acetates is one of the most usual reasons of catalytic deactivation in these types of reactions, promoting the coke formation on the catalytic surface. ${ }^{45}$ Furthermore, the likely active site blockage by acetate species is suggested to be the reason of the conversion decrease with all the aluminosilicates, mainly below $2 \mathrm{~h}$. For instance, this fact is supported and emphasized by the results obtained with the MFI2 zeolite. Thus, this material favours the formation of acetic acid in a greater extent, implying higher acetate adsorption that leads to higher conversion drop at initial times $\left(k_{d}=0.733 \mathrm{~h}^{-1}\right)$. However, regarding all the catalysts, once the strong acid sites become strongly saturated by mainly acetate species, the selectivity to acetic acid decreases but keeps within $5 \%$ range over $2 \mathrm{~h}$. This means, in terms of acetone conversion, reduction of the deactivation rate $\left(k_{d}=\right.$ $0.113 \mathrm{~h}^{-1}$; drop of $101 \%$ regarding TOS $<2 \mathrm{~h}$ ). DRIFTS analyses confirm the $\beta$-scission mechanism via acetate species.

Both zeolite structures (MFI and BEA) act as molecular sieve in the case of mesitylene ( $0.87 \mathrm{~nm}$ of kinetic diameter), ${ }^{46}$ which cannot be formed inside the channels, since it is larger than the pore-limiting diameter of both zeolite structures (Table 1). Thus, the mesitylene formation only occurs on the active sites located on the external surface of both MFI and BEA zeolites (i.e., not all the protons of these materials can act as mesitylene forming sites). Based on this, the selectivity to mesitylene becomes more relevant as deactivation is produced because of the blockage of the active sites located inside the channels by the formation of $\mathrm{C} 6$ molecules and, mainly, acetate intermediates. However, in the case of the MCM-41, the channels are wide enough, therefore the mesitylene is formed on the whole surface of the catalyst (without molecular sieve behaviour), implying a good performance despite owning lower overall concentration of protons than both MFI1 and BEA zeolites (Table 1).

After unravelling the role of the $\mathrm{C} 6 \beta$-scission reaction in the yield of the desired route (black colour part in Scheme 1), further analysis of the aldol condensation reaction to target product must be considered. Thus, selectivity for $\mathrm{C} 6$ to $\mathrm{C} 9$ pools of each material was examined between the two aldol condensation steps of the desired
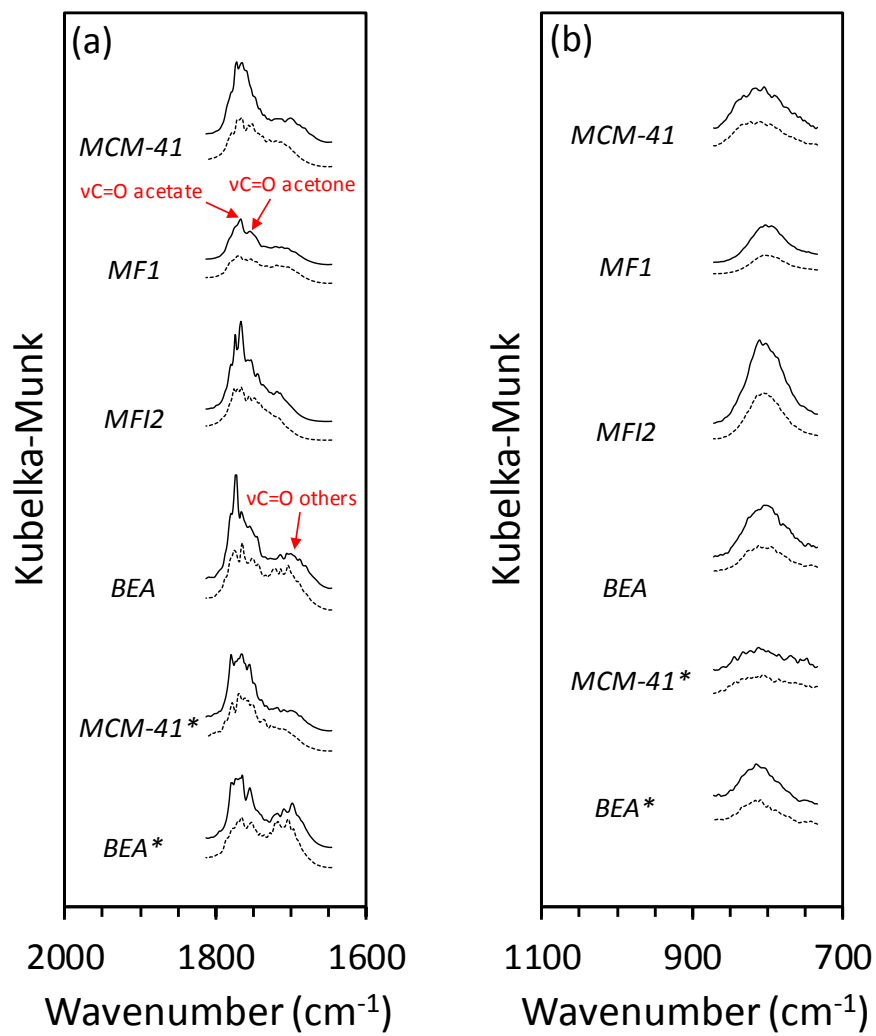

Figure 6. DRIFT spectra obtained in the gas-phase acetone selfcondensation for (a) $\mathrm{VC}=\mathrm{O}$ bands $\left(1736,1726\right.$ and $1650-1700 \mathrm{~cm}^{-1}$ corresponding to acetate, acetone and other species, respectively) and (b) vC-C band of acetate $\left(750-840 \mathrm{~cm}^{-1}\right)$. Dashed lines: $0.5 \mathrm{~h}$; solid lines: $4 \mathrm{~h}$. * Results corresponding to $\mathrm{H}_{2}$ co-feeding experiments. 


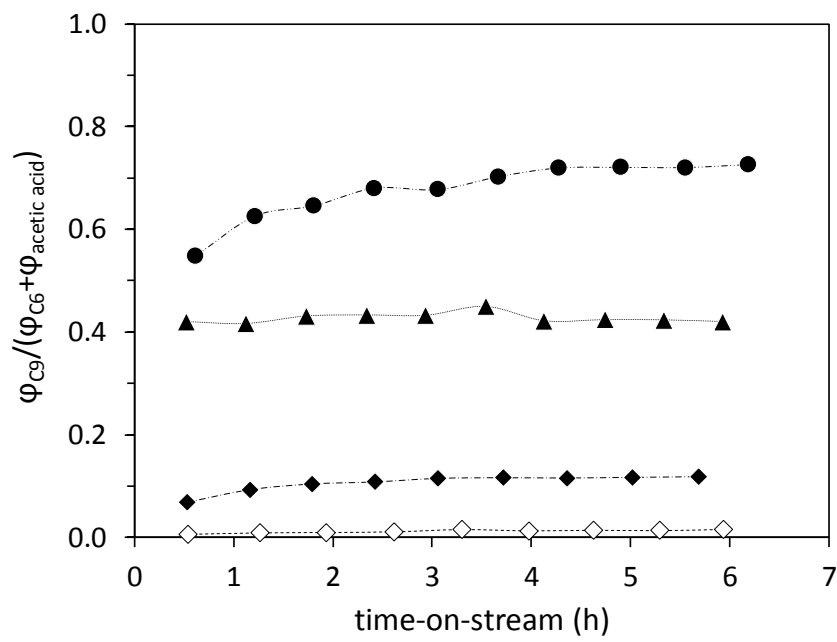

Figure 7. Evolution of the selectivity to the C9-pool with regard to the selectivity to $\mathrm{C} 6$ precursors with the time-on-stream in the gas-phase acetone self-condensation at $573 \mathrm{~K}\left(\mathrm{WHSV}=7.8 \mathrm{~h}^{-1}\right)$. Symbols: $\mathrm{MCM}-41$,

$\checkmark \mathrm{MFI}, \diamond \mathrm{MFI}$, and $\boldsymbol{\Delta}$ BEA. The consumption of $\mathrm{C} 6$ by the $\beta$-scission reaction is corrected by adding the acetic acid selectivity to the C6-pool selectivity.

reaction (acetone to $\mathrm{C6}$, and $\mathrm{C} 6$ to $\mathrm{C9}$ ). This analysis was selected since the target product (mesitylene) is a C9 compound and its production can be conditioned by shape constraints of some of the materials tested to produce it (zeolites). The evolution of the selectivity to the C9-pool regarding the selectivity to all of the produced $\mathrm{C} 9$ precursors is depicted in Figure 7. Considering the $\mathrm{C} 6$ $\beta$-scission as an undesired reaction taking part from $\mathrm{C} 6$ in parallel with the C9 formation, the quantification of the potential total amount of $\mathrm{C} 6$ requires considering also the $\mathrm{C} 6$ suffering this reaction. This fraction is evaluated by quantifying the acetic acid obtained (stoichiometric factor 1:1), being this selectivity added to the C6-pool (denominator). The highest values are achieved with the MCM-41. Moreover, an increasing trend is noticed with the MCM-41, MFI1, and MFI2 materials, being more relevant with the MCM-41 (from $0.55,0.07$, and 0.01 to $0.73,0.12$, and 0.02 , respectively). In the case of the MCM-41, this fact might be explained because all the active sites (whether inside or outside channels) can catalyse the formation of C9 compounds since there is not lacking shape constraints. As deactivation occurs due to strong adsorption of acetates on the sites that promote the $\mathrm{C} 6 \beta$-scission reaction, a higher relative amount of C6 is able to be converted to C9 species by aldol condensation reaction. Accordingly, the selectivity to the main route is favoured, obtaining C9 compounds in a higher extent.

The same explanation as for the MCM-41 would be applied to both MFI zeolites, since similar behaviour is observed (Figure 7). In this case, size limitations of the MFI framework only allow outside sites to be active for the target reaction. Nevertheless, as aforementioned, protons located inside the intersection of channels are able to catalyse acetone aldol condensation to $\mathrm{C} 6$ species and subsequent $\beta$-scission reaction, but only products of the latter can diffuse throughout the channels. Consequently, as deactivation takes place (owing to acetates yielded by C6 $\beta$-scission), the relative quantity of $\mathrm{C} 6$ species on the outside surface of the MFI zeolite increases. Therefore, the selectivity to the main route raises, implying higher relative formation of $\mathrm{C} 9$ compounds. On the other hand, the increase with the reaction time is lower than that reached with the MCM-41 in absolute terms, since not all the acid sites of the MFI zeolites are physically available for the reactants. However, values are almost constant with the time-on-stream with BEA (0.42).

Although the same explanation as for the MCM-41 and MFI zeolites is considered for the outside surface of BEA, shape selectivity is completely different for this zeolite framework. In fact, the first aldol condensation step (acetone to $\mathrm{C} 6$ ) and subsequent $\mathrm{C} 6 \beta$-scission can be catalysed by the active sites located inside channels, resulting $\mathrm{C} 6$ species that are able to diffuse through them. As well as deactivation occurs (reducing the activity of the $\mathrm{C} 6 \beta$-scission by strong adsorption of acetates intermediates), the C6 compounds formed inside the channels can diffuse more efficiently to outside. In this light, the enhancement of the main route observed with the rest of the materials could be masked by the diffusion of inside-formed C6, albeit the substantial improvement observed in the analysis of mesitylene and C9-pool selectivities in Figure $\mathbf{2}$ and Table $\mathbf{6 6}$.

\section{Influence of $\mathrm{H}_{\mathbf{2}}$ co-feeding on the catalytic performance}

Operating under reducing atmosphere (i.e., $\mathrm{H}_{2}$ supplying) was evaluated with the aim of improving the catalytic stability and also exploring possible changes in the selectivity to the main and side routes (Scheme 1 ). The capacity of free-metal aluminosilicates for activating hydrogen was previously observed by Meusinger and Corma. ${ }^{28}$ These authors considered that Brønsted acid sites of aluminosilicates cleavage $\mathrm{C}-\mathrm{H}$ bonds implying formation of carbonium ions, which loses $\mathrm{H}_{2}$, leading to carbenium ions adsorbed on the solid surface. ${ }^{39}$ The inverse pathway, which implicates the $\mathrm{C}=\mathrm{C}$ hydrogenation by the active hydrogen produced on the zeolite surface, has been theoretically proved, assuming it as the explanation for the acid-catalysed hydrogenation of olefins. ${ }^{29,30}$ Therefore, the $\mathrm{H}_{2}$ supplying to the reaction medium may involve a partial different catalytic behaviour than that previously observed in inert conditions.

In this set of experiments, both MFI zeolites were ruled out, because of their constraints previously shown with reference to both acetone conversion and selectivity towards mesitylene. Furthermore, the experiments were performed up to $4.5 \mathrm{~h}$, since the behaviour observed with MCM-41 and BEA over this reaction time, in absence of $\mathrm{H}_{2}$, was almost constant.

Methyl isobutyl ketone and diisobutyl ketone (MIBK and DIBK, respectively) were determined among the reaction products with both catalysts. These reaction products are formed by hydrogenation side-reactions of mesityl oxide and phorones, respectively. Thus, this confirms the ability of aluminosilicates to activate the hydrogen molecule, and to perform $\mathrm{C}=\mathrm{C}$ hydrogenation, according to that aforementioned. Indeed, MIBK selectivities are 0.6 and $0.4 \%$ at initial times, and decreased to values of 0.4 and $0.2 \%$ at the end of the experiment, with MCM- 41 and BEA, respectively. The selectivities to DIBK are 1.6 and $3.8 \%$ at initial times, and decreased to 0.7 and $1.4 \%$ at the end of the experiment, with MCM-41 and BEA, respectively.

The acetone conversion evolution with the time-on-stream is shown in Figure 8. Values of 15.1 and $21.5 \%$ are achieved at initial times (i.e., 


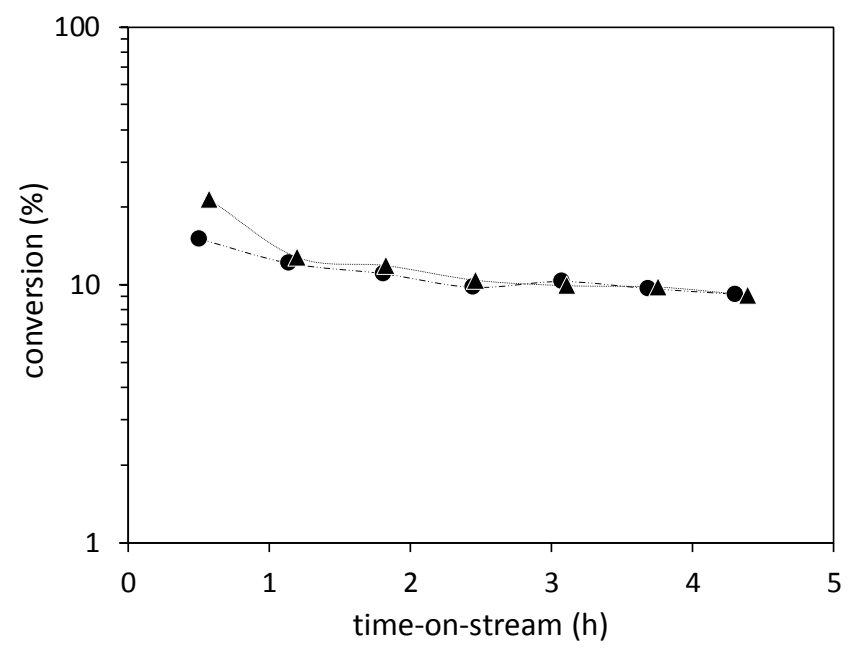

Figure 8. Acetone conversion evolution with the time-on-stream in the gas-phase acetone self-condensation at $573 \mathrm{~K}$ in presence of $\mathrm{H}_{2}$ (WHSV $=7.8 \mathrm{~h}^{-1}$ ). Symbols: $-\mathrm{MCM}-41$, and $\boldsymbol{\Delta}$ BEA. Lines are meant to guide the eye.

at the first measurement; corresponding to 16.7 and $26.0 \%$ estimated at zero time) with MCM-41 and BEA, respectively. These acetone conversion results imply enhancements of 60.6 and $53.6 \%$ regarding those initially reached in absence of $\mathrm{H}_{2}$. Additionally, lower deactivation is observed $\left(k_{d}\right.$ of 0.239 and $0.471 \mathrm{~h}^{-1}$ for MCM-41 and $\mathrm{BEA}$, respectively, below $2 \mathrm{~h}$ ), comparing to that noticed working in inert conditions ( $k_{d}$ of 0.262 and $0.578 \mathrm{~h}^{-1}$ for MCM-41 and BEA, respectively). Thus, conversions decrease 39.1 and $57.2 \%$ from initial times to $\sim 6 \mathrm{~h}$ (conversion of $9.2 \%$ with both catalysts), with MCM41 and $B E A$, respectively. Within the same range of time-on-stream, the drops noticed in absence of $\mathrm{H}_{2}$ are 41.5 and $61.4 \%$ with MCM-41 and $\mathrm{BEA}$, respectively. Therefore, it can be stated that the presence of $\mathrm{H}_{2}$ slightly improved the catalytic stability and, mainly, the catalytic activity of both aluminosilicates, in terms of acetone conversion.

The selectivity to mesitylene is enhanced (Figure 9), reaching values of 23.6 and $18.7 \%$ at initial times with MCM- 41 and BEA, respectively. DRIFTS experiments also prove that the formation of mesitylene is improved when $\mathrm{H}_{2}$ is co-fed, since the intensities of the mesitylene bands are higher than those noted operating in inert conditions (Figure S4). The rising trend of the selectivity to mesitylene is softer with both materials, comparing with those noticed in inert conditions, achieving final selectivities of 29.2 and $24.4 \%$ with MCM41 and BEA (keeping constant over $3.1 \mathrm{~h}$ with this last catalyst), respectively. The amount of mesitylene formed, relative to the C9pool, is much lower than that accomplished in absence of $\mathrm{H}_{2}$ (Figure 10). Thus, the mesitylene/C9 selectivity ratio slightly increases from 0.50 to 0.56 during the whole experiment with MCM-41, while it raises from 0.42 to 0.55 , and keeps this value almost constant over $1.1 \mathrm{~h}$ with BEA. Isophorones are the main compounds among the rest of the C9 species (phorones and isophorones), reaching selectivities around $50 \%$ higher than that achieved by phorones (Table S7-S8). Therefore, it can be stated that the presence of $\mathrm{H}_{2}$ hinders the mesitylene formation from the $\mathrm{C} 9$ precursors by stabilizing different transition states comparing with those stabilized in absence of $\mathrm{H}_{2}$. This implies higher selectivity to the rest of C9 species (especially the corresponding to isophorones). Indeed, it is suggested that the active

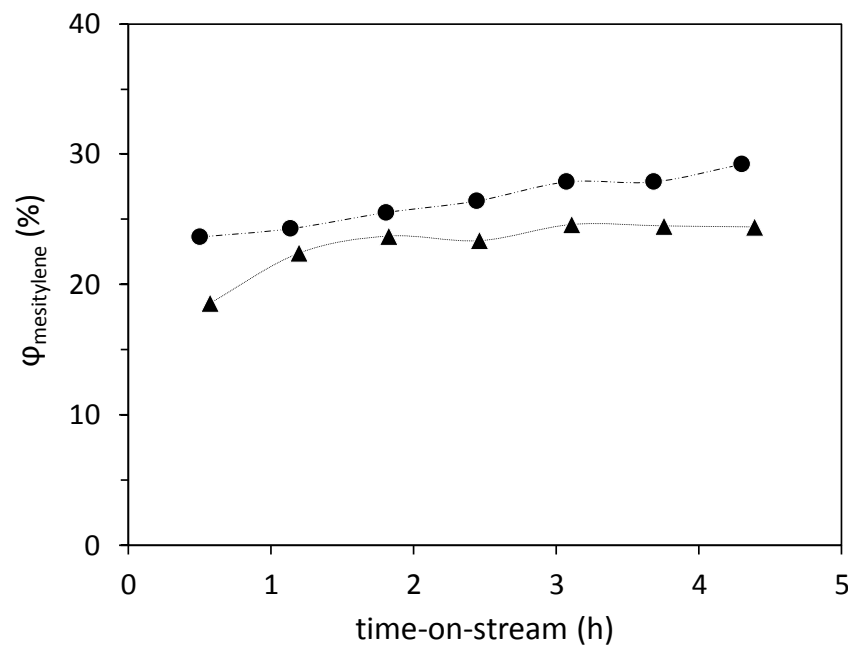

Figure 9. Evolution of the selectivity to mesitylene with the time-on-stream in the gas-phase acetone self-condensation at $573 \mathrm{~K}$ in presence of $\mathrm{H}_{2}\left(\mathrm{WHSV}=7.8 \mathrm{~h}^{-1}\right)$. Symbols: $\mathrm{MCM}-41$, and $\Delta$ BEA. Lines are meant to guide the eye.

sites are likely to be interacting with hydrogen atoms because of the proved ability of the aluminosilicates to activate $\mathrm{H}_{2}$ (entailing higher concentration of hydrogen adatoms on the catalytic surface). When $\mathrm{H}_{2}$ is co-fed, part of the sites (which are active in inert conditions) could be: (i) inactive due to the blockage by hydrogen atoms; or (ii) less active, being reduced their TOF. Based on this, the acid activity of the aluminosilicates is reduced, hence diminishing their dehydration capacity. Thus, by the combination of this hypothesis and the results obtained, it is confirmed that the isophorone-tomesitylene dehydration route is quite relevant when operating in inert conditions.

Concerning the selectivities to the C6-pool and acetic acid (Figure 11), the same trends, as those noticed in inert conditions, are observed when $\mathrm{H}_{2}$ is co-fed. Moreover, almost the same selectivities to $\mathrm{C} 6$ as those reached in absence of $\mathrm{H}_{2}$ are achieved during the

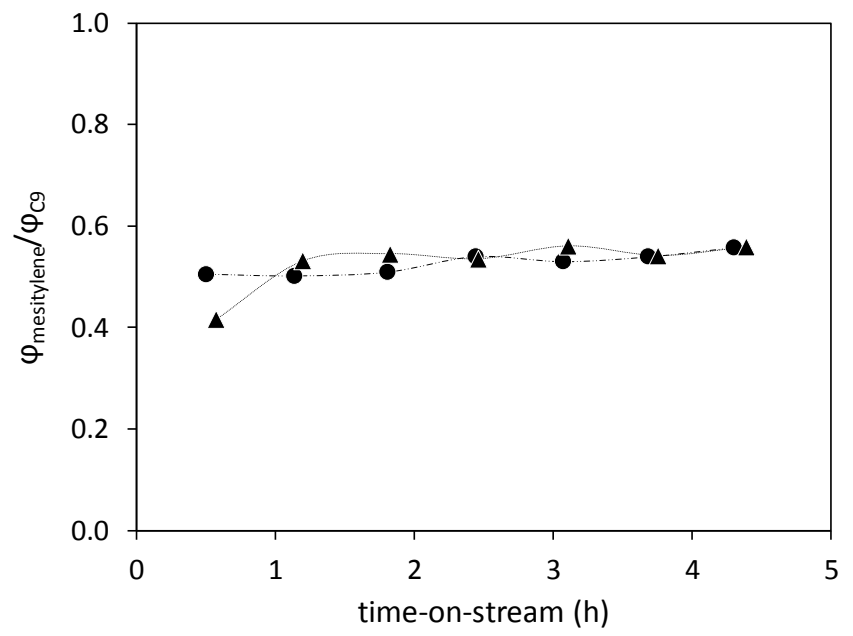

Figure 10. Evolution of the mesitylene/C9-pool selectivity ratio with the time-on-stream in the gas-phase acetone self-condensation at $573 \mathrm{~K}$ in presence of $\mathrm{H}_{2}\left(\mathrm{WHSV}=7.8 \mathrm{~h}^{-1}\right)$. Symbols: MCM-41, and $\boldsymbol{\Delta}$ BEA. Lines are meant to guide the eye. 


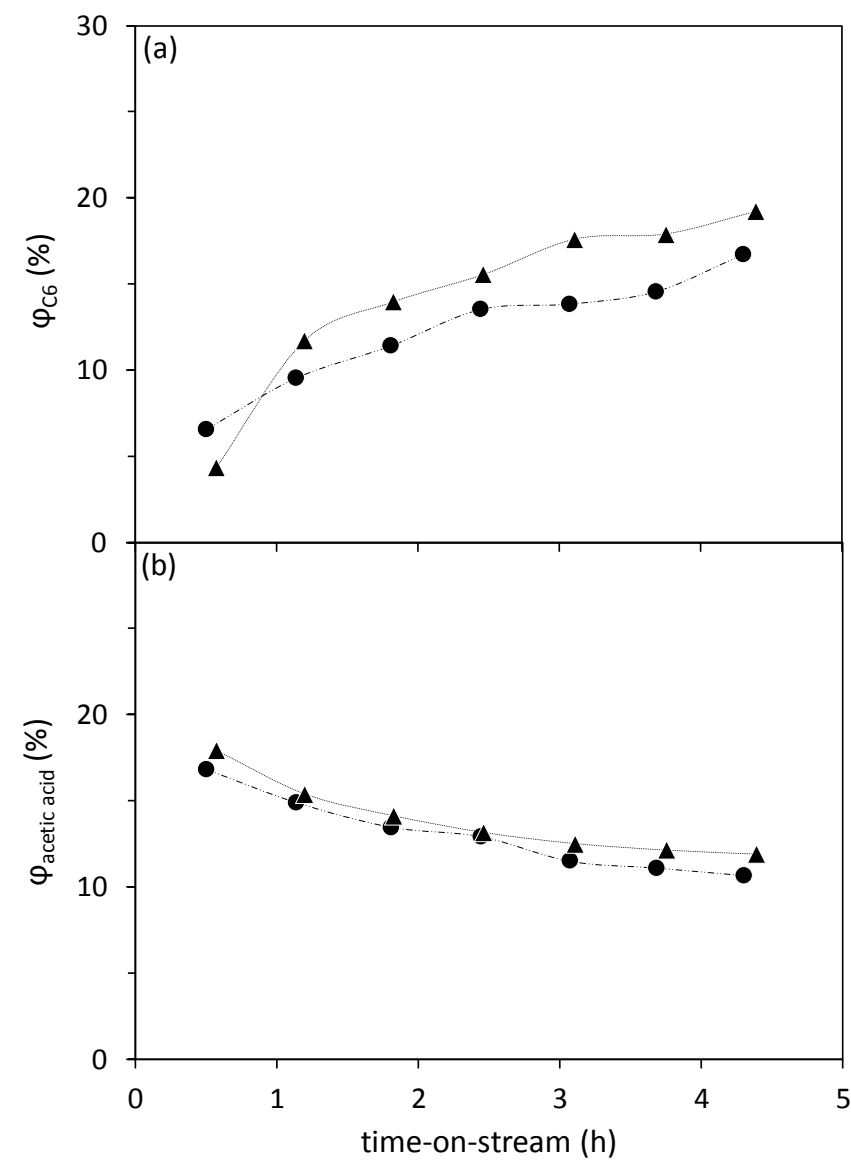

Figure 11. Evolution of the selectivity to (a) C6-pool and (b) acetic acid with the time-on-stream in the gas-phase acetone self-condensation at $573 \mathrm{~K}$ in presence of $\mathrm{H}_{2}\left(\mathrm{WHSV}=7.8 \mathrm{~h}^{-1}\right)$. Symbols: $\bullet \mathrm{MCM}-41$, and $\boldsymbol{\Delta}$ $\mathrm{BEA}$. Lines are meant to guide the eye.

reaction time. However, the $\beta$-scission reaction is hindered in presence of hydrogen for both catalysts. Thus, the highest acetic acid selectivity values reached at initial times (16.8 and $17.9 \%$ with MCM41 and BEA, respectively) are similar to those achieved around $4.2 \mathrm{~h}$ in absence of $\mathrm{H}_{2}$ (operating conditions that produce relevant catalytic deactivation). The selectivities to acetic acid at zero time (Figure 5) are 18.4 and $19.7 \%$, respectively. The acetic acid formation rates per proton at zero time are almost the same as those obtained in inert conditions (9.9 $10^{-20}$ and $8.810^{-20} \mathrm{mmol} \mathrm{H}^{+-1} \mathrm{~h}^{-1}$ ), otherwise the acetone reaction rate per proton at zero time are much higher when $\mathrm{H}_{2}$ is co-fed (improvements of 51 and $30 \%$ for MCM-41 and BEA, respectively). DRIFTS analyses (Figure 6) show that the intensities of the absorption bands related to acetates $(\mathrm{VC}=\mathrm{O}$ and $\mathrm{VC}-\mathrm{C}$ at 1736 and $750-840 \mathrm{~cm}^{-1}$, respectively) increase in a lower extent during the reaction comparing with operating in inert conditions. This evinces the role of the $\mathrm{H}_{2}$ presence in the hindrance of the acetic acid formation by $\beta$-scission reaction of $\mathrm{C} 6$ intermediates, which would be justified by the same explanation as for the mesitylene hampering (active site blockage by hydrogen adatoms and/or lower TOF for this reaction). In this light, the selectivity to the aldol condensation pathway to $\mathrm{C} 9$ species is favoured by co-feeding $\mathrm{H}_{2}$, regarding the $\mathrm{C} 6$ $\beta$-scission route, resulting in higher formation of the C9-pool. Consequently, although the presence of $\mathrm{H}_{2}$ implies lower

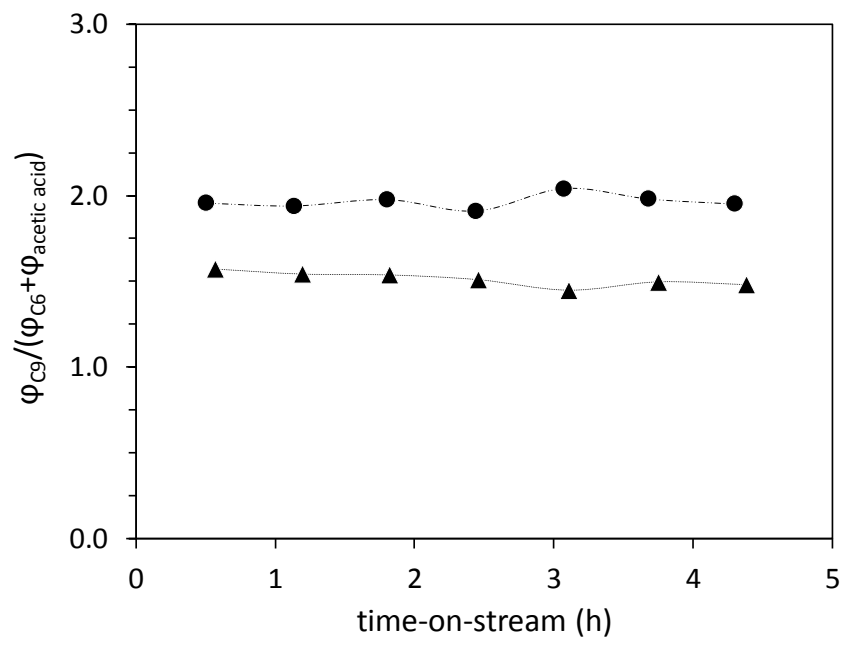

Figure 12. Evolution of the selectivity to the C9-pool with regard to the selectivity to $\mathrm{C} 6$ precursors with the time-on-stream in the gas-phase acetone self-condensation at $573 \mathrm{~K}$ in presence of $\mathrm{H}_{2}\left(\right.$ WHSV $=7.8 \mathrm{~h}^{-1}$ ). The consumption of $\mathrm{C} 6$ by the $\beta$-scission reaction is corrected by adding the acetic acid selectivity to the C6-pool selectivity.

mesitylene/C9-pool selectivity ratio comparing with inert conditions (from 0.78 and 0.85 to 0.56 and 0.55 with MCM-41 an BEA, respectively), the formation of mesitylene is enhanced in absolute terms (59 and 101\% with MCM-41 and BEA, respectively).

The aldol condensation activity of both MCM- 41 and BEA in presence of $\mathrm{H}_{2}$ was also assessed. The evolution with the reaction time of the selectivity to the C9-pool regarding the selectivity to all of the produced C9 precursors is depicted in Figure 12. Results confirm the enhancement accomplished with regard to the desired reaction pathways when $\mathrm{H}_{2}$ is co-fed (improvement of the aldol condensation activity), since values much higher than those obtained in inert conditions are achieved (1.96 and 1.51 with MCM-41 and BEA, respectively). With the $\mathrm{MCM}-41$, in contrast to the increasing trend noticed in inert conditions, values are kept constant. This different behaviour is suggested to be due to the presence of $\mathrm{H}_{2}$ that leads to higher selectivity to the target route entailing lower activity for the C6 $\beta$-scission reaction and subsequent catalytic deactivation by the resulting acetate intermediates. However, co-feeding $\mathrm{H}_{2}$ also implies lower dehydration capacity of the materials. Relative selectivities of isophorones and mesitylene concerning their respectively $\mathrm{C} 9$ precursors (i.e., phorones and the sum of phorones and isophorones, respectively) both in absence and presence of $\mathrm{H}_{2}$ using the MCM-41 and BEA are summarized in Table S9. Values obtained operating in presence of $\mathrm{H}_{2}$ are much lower than those corresponding to inert conditions (around 50 and $80 \%$ lower with MCM-41 and BEA, respectively). These results evince the detrimental side-effect of the $\mathrm{H}_{2}$ co-feeding on the dehydration steps, which can be also noticed by direct comparison of the selectivity to both isophorones and mesitylene in absence and presence of $\mathrm{H}_{2}$ for MCM-41 and BEA (summarized in Table S3-S7 and Table S6-S8, respectively).

\section{Conclusions}

The acetone self-condensation catalysed by aluminosilicates (MCM-41 and BEA), allows obtaining promising results for the 
selective production of mesitylene. The formation of this compound is highly enhanced comparing the results achieved when using basic heterogeneous catalysis, because of the higher dehydration capacity of aluminosilicates (conferred by their intrinsic acid nature). Nevertheless, the high concentration of acid sites favours the performance of the $\beta$-scission sidereaction of the C6-pool (mainly confirmed by the MFI2 zeolite), leading to the formation of undesired acetic acid and isobutene. Furthermore, the acetate species involved in this mechanism, imply catalytic stability loss with all the tested catalysts due to strong adsorption (supported by DRIFTS analyses), which can promote coke formation. Both MFI1 and MFI2 zeolites are discarded because of their constraints to promote acetone conversion and mesitylene formation. MCM-41 and BEA can activate $\mathrm{H}_{2}$, observing low amounts of MIBK and DIBK. The presence of $\mathrm{H}_{2}$ hampers the $\beta$-scission of the $\mathrm{C} 6$-pool, favouring the subsequent $\mathrm{C}-\mathrm{C}$ bond forming reactions (production of $\mathrm{C} 9$ compounds) and, therefore, improving the mesitylene obtainment (59 and 101\% with MCM-41 and BEA, respectively).

\section{Conflicts of interest}

There are no conflicts to declare.

\section{Acknowledgements}

Funding from the Ministry of Science, Innovation and Universities of the Government of Spain (CTQ2017-89443-C3-2$\mathrm{R})$ and the regional Government of the Principality of Asturias (IDI/2018/000116).

\section{References}

1. A. Dennig, A. M. Weingartner, T. Kardashliev, C. A. Müller, E. Tassano, M. Schürmann, A. J. Ruff and U. Schwaneberg, Chem. Eur. J., 2017, 23, 17981-17991.

2. A. N. Kazakova, R. O. lakovenko, I. A. Boyarskaya, V. G. Nenajdenko and A. V. Vasilyev, J. Org. Chem., 2015, 80, 95069517.

3. G. Capocasa, G. Olivo, A. Barbieri, O. Lanzalunga and S. Di Stefano, Catal. Sci. Technol., 2017, 7, 5677-5686.

4. A. A. Ozerenko, N. Y. Usachev, I. M. Krukovskii, A. M Gyul'maliev, E. A. Ozerenko and M. N. Kkrasnykh, Pet. Chem., 2007, 47, 32-38.

5. M. I. M. Alzeer, K. J. D. MacKenzie and R. A. Keyzers, Micropor. Mesopor. Mat., 2017, 241, 316-325.

6. J. Xu, L. Shi, J. Wang, S. Lu, Y. Wang, G. Gao and S. Ding, Carbon, 2018, 138, 348-356.

7. H. W. Earhart and A. P. Komin, in Kirk-Othmer Encyclopedia of Chemical Technology; Ed. C. Ley; John Wiley \& Sons, Inc., 2000, p. 2-13.

8. N. S. Khashagul'gova, L. D. Konoval'chikov, B. K. Nefedov, A. D. Sulimov and D. M. Bychkova, Chem. Technol. Fuel. Oil., 1991, 27, 477-480.

9. B. C. Berris, Patent US5292969A (Mar. 8, 1994), Phenolic antioxidant and process, Current assignee: Albemarle Corp.

10. R. B. Warner and J. W. Slater, Patent GB2124198A (Feb. 15 1984), Plant growth regulating method, Current assignee: Orica Ltd., Imperial Chemical Industries Ltd.
11. A. C. Reeve, Patent US5107020A (Apr. 21, 1992), Method for producing purified trimesic acid, Current assignee: BP Corporation North America Inc.

12. J. F. Knifton and R. M. Suggitt Patent US3906045A (Sept. 16, 1975), Homogeneous ruthenium catalysts useful in the selective reduction of nitroaromatics to amines, Current assignee: Texaco Inc.

13. W. R. Moser Patent US3894141A (July 8, 1975), Process for removing nitric oxide, Current assignee: ExxonMobil Research and Engineering Co.

14. S. Ordóñez, E. Díaz, M. León and L. Faba, Catal. Today, 2011, 167, 71-76.

15. S. Herrmann and E. Iglesia, J. Catal., 2017, 346, 134-153.

16. L. Faba, E. Díaz and S. Ordóñez, Appl. Catal. B 2013, 142-143, 387-395.

17. M. León, L: Faba, E. Díaz, S. Bennici, A. Vega, S. Ordóñez, and A. Auroux, Appl. Catal. B, 2014, 147, 796-804.

18. M. Zamora, T. López, M. Asomoza, R. Meléndrez and R. Gómez, Catal. Today, 2006, 116, 234-238.

19. V. K. Díez, C. R. Apesteguía and J. I. Di Cosimo, Stud. Surf. Sci. Catal., 2001, 139, 303-310.

20. S. Sifniades, A. B. Levy and H. Bahl, In Ullmann's Encyclopedia of Industrial Chemistry; Elvers, B., Ed.; Wiley-VCH Verlag GmbH \& Co. KGaA, 2009; Vol. 1, Acetone, p. 3.

21. X. Sheng, N. Li, G. Li, W. Wang, A. Wang, Y. Cong, X. Wang, and T. Zhang, Green Chem., 2016, 18, 3707-3711.

22. T. T. N. Nguyen, V. Bellière-Baca, P. Rey and J. M. M: Millet, Catal. Sci. Technol., 2015, 5, 3576-3584.

23. D. Suttipat, W. Wannapakdee, T. Yutthalekha, S Ittisanronnachai, T. Ungpittagul, K. Phomphrai, S. Bureekaew and C. Wattanakit, Appl. Mater. Interfaces 2018, 10, 1635816366

24. J. S. López, R. A. Dagle, V. L. Dagle, C. Smith and K. O Albrecht, Catal. Sci. Technol., 2019, 9, 1117-1131.

25. H. Hernando, C. Ochoa-Hernández, M. Schmzhy, I. Moreno, J. Fermonos, P. Pizarro, J. M. Coronado, J. Cejka and D. P. Serrano, Catal. Sci. Technol., 2019, 9, 789-802.

26. Z. He, J. Wu, B. Gao, and H. He, ACS Appl. Mater. Interfaces, 2015, 7, 2424-2432.

27. S. Wang and E. Iglesia, ACS Catal., 2016, 6, 7664-7684.

28. J. Meusinger and A. Corma, J. Catal., 1995, 152, 189-197.

29. J. Kanai, J. A. Martens and P. A. Jacobs, J. Catal., 1992, 133 527-543.

30. J. Quesada, L. Faba E. Díaz and S. Ordóñez, J. Catal., 2019, 377 133-144. (44)

31. R. Xu, W. Pang, J. Yu, Q. Huo and J. Chen, In Chemistry of Zeolites and Related Porous Materials; John Wiley \& Sons (Asia) Pte Ltd., Singapore, 2007; p. 44.

32. Z. Song, Y. Huang, W. L. Xu, L. Wang, Y. Bao, S. Li and M. Yu, Sci. Rep., 2015, 5, 13981.

33. L. Kubelková and J. Nováková, J. Mol. Catal., 1992, 75, 53-62.

34. M. Guisnet and P. Magnoux, Catal. Today, 1997, 36, 477-483.

35. E. Dumitriu, V. Hulea, I. Fechete, A. Auroux, J. -F. Lacaze and C. Guimon, Micropor. Mesopor. Mat. 2001, 43, 341-359.

36. A. Corma, Chem. Rev., 1997, 97, 2373-2419.

37. S. Fujiyama, S. Seino, N. Kamiya, K. Nishi, K. Yoza and Y. Yokomori, Phys. Chem. Chem. Phys. 2014, 16, 15839-15845.

38. E. Kose, A. Atac, M. Karabacak, P. B. Nagabalasubramanian, A. M. Asiri and S. Periandy, Spectrochim. Acta A, 2013, 116, 622634.

39. H. Zhang, M. Y. S. Ibrahim and D. W. Flaherty, J. Catal., 2018 361, 290-302.

40. J. I. Di Cosimo, C. R. Apesteguía, M. J. L. Ginés and E. Iglesia, J. Catal., 2000, 190, 261-275.

41. S. Herrmann and E. Iglesia, J. Catal., 2018, 360, 66-80.

42. C. Drouilly, J. -M. Krafft, F. Averseng, H. Lauron-Pernot, C. Bazer-Bachi, C. Chizallet, V. Lecocq and G. Costentin, Catal. Today, 2013, 205, 67-75. 
43. J. Quesada, L. Faba, E. Díaz, S. Bennici, A. Auroux and S. Ordóñez, J. Catal., 2015, 329, 1-9.

44. G. Stogiannidis, S. Tsigoias, P. Mpourazanis, S. Boghosian, S. Kaziannis and A. G. Kalampounias, Chem. Phys., 2019, 522, 19.

45. D. E. Resasco, B. Wang and S. Crossley, Catal. Sci. Technol., 2016, 6, 2543-2559.

46. A. Li, T. Boucheron, A. Tuel, D. Farrusseng and F. Meunier, Chem. Commun., 2014, 50, 1824-1826. 